\title{
Immune Checkpoint Inhibitor-Induced Gastroduodenitis: Recurrence after Rechallenge with Pembrolizumab
}

\author{
Catarina O'Neill $^{a}$ Rui Mendo ${ }^{a}$ Pedro C. Figueiredo ${ }^{a, b}$ \\ ${ }^{a}$ Department of Gastroenterology, Centro Hospitalar Lisboa Ocidental, Hospital de Egas Moniz, Lisbon, Portugal; \\ ${ }^{b}$ Department of Gastroenterology, Hospital da Luz, Lisbon, Portugal
}

\section{Keywords}

Immune checkpoint inhibitors · Pembrolizumab · Immunerelated adverse events · Gastroduodenitis

\section{Gastroduodenite associada aos Inibidores dos Checkpoints Imunológicos: recorrência após reintrodução de pembrolizumab}

\section{Palavras Chave}

Inibidores dos checkpoints imunológicos .

Pembrolizumab · Eventos adversos imunológicos .

Gastroduodenite

\section{Dear Editor,}

We present with great interest the follow-up of a case report published in the Portuguese Journal of Gastroenterology under the section Images in Gastroenterology and Hepatology [1].

A 44-year-old male undergoing immunotherapy with pembrolizumab for metastatic non-small cell lung carcinoma developed gastroduodenitis induced by an immune checkpoint inhibitor (ICI). He was treated with 2 consecutive courses of oral corticosteroids until endo- scopic resolution. Treatment with pembrolizumab infusions was restarted after prednisolone had been completely tapered. After 3 cycles the patient presented dysphagia, bloating, nausea, and vomiting. He thus underwent an esophagogastroduodenoscopy which revealed a diffusely edematous and erythematous mucosa with friability and large patches of white coating, suggestive of relapse of pembrolizumab-induced gastritis as shown in Figure 1. The endoscopic findings were similar to the ones previously encountered. Histological examination excluded other etiologies, namely infection and neoplasia. Pembrolizumab was discontinued and prednisolone was initiated $(1 \mathrm{mg} / \mathrm{kg} /$ day with a taper over 8 weeks), with symptomatic improvement within a few days. The patient is currently awaiting endoscopic reevaluation before a new pembrolizumab rechallenge.

Lower gastrointestinal (GI) immune-related adverse events (irAE) are well known toxicities of ICI; however, upper GI involvement is not commonly reported $[2,3]$. Significant GI irAE are less frequent for anti-PD-1/L1 agents (up to 2\%) than for CTLA-4 agents or combination regimens $[2,3]$. The severity of the adverse events reported in this case was classified as grade 2 according to the National Cancer Institute CTCAE [4]. There are no

\section{(c) 2021 Sociedade Portuguesa de Gastrenterologia.} Published by S. Karger AG, Basel

This is an Open Access article licensed under the Creative Commons Attribution-NonCommercial-4.0 International License (CC BY-NC) (http://www.karger.com/Services/OpenAccessLicense), applicable to the online version of the article only. Usage and distribution for commercial purposes requires written permission.
Correspondence to:

Catarina O’Neill, oneill.catarina@gmail.com 


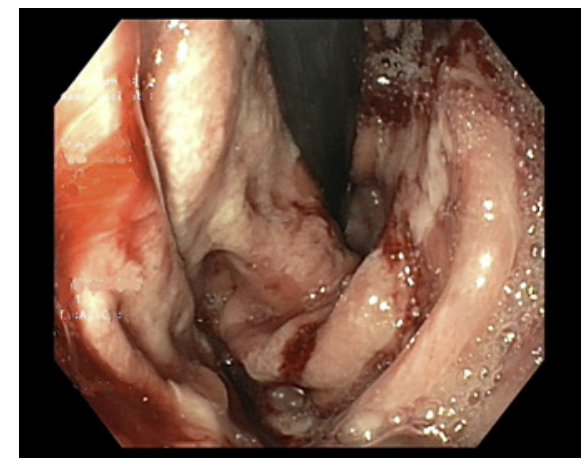

Fig. 1. Esophagogastroduodenoscopy after rechallenge with pembrolizumab. The gastric mucosa was diffusely edematous and friable, with extensive areas covered with white exudate.

established guidelines for the management of upper GI tract irAE, and the generally adopted strategy for symptoms of grade 2 or higher is similar to that for colitis, i.e., withholding ICI administration and initiation of systemic corticosteroids or additional immunosuppressive agents for steroid refractory cases (e.g., infliximab or vedolizumab) $[2,5,6]$. After appropriate management, the key point lies in when to restart ICI after an irAE, since it is of crucial importance for treatment and patient prognosis. However, limited data are available to support the clinician's decision. Dolladille et al. [7] reported a recurrence rate of $28.6 \%$ for the same irAE after restarting the same anti-PD-1 monotherapy in patients with all types of cancer, but the recurrence rate seems to be lower for GI irAE $[5,8]$. Current guidelines recommend managing irAE based on their severity. Resuming PD-1/L1 agents is an option after grade 3 or lower grade adverse events, pro- vided that patient can recover to grade 1 or lower. On the other hand, all ICI should be permanently discontinued in grade 4 toxicities [5]. No guidelines currently support iterative rechallenge in patients with persistent recurrence of irAE.

Ultimately, the decision to restart ICI after an irAE must be discussed within a multidisciplinary team on an individual basis, taking into account the malignancy progression/stability and the expected efficacy and potential risk of ICI rechallenge, along with appropriate monitoring and treatment of potential irAE.

\section{Statement of Ethics}

The authors have no ethical conflicts to disclose.

\section{Conflict of Interest Statement}

The authors have no conflict of interests to declare.

\section{Funding Sources}

The authors have no funding sources to declare.

\section{Author Contributions}

Catarina O'Neill: analysis and review of the literature and drafting of this paper. Rui Mendo: review of this paper and approval of the final version. Pedro C. Figueiredo: patient follow-up and decisive intervention in the therapeutic strategy, critical review of this paper and approval of the final version.

\section{References}

1 Mendo R, Figueiredo P, Mascarenhas L. Checkpoint inhibitor-induced gastroduodenitis: An unusual manifestation. GE Port J Gastroenterol. 2020;1-3.

2 Kröner PT, Mody K, Farraye FA. Immune checkpoint inhibitor-related luminal GI adverse events. Gastrointest Endosc. 2019 Dec; 90(6):881-92.

3 Tang T, Abu-Sbeih H, Luo W, Lum P, Qiao $\mathrm{W}$, Bresalier RS, et al. Upper gastrointestinal symptoms and associated endoscopic and histological features in patients receiving immune checkpoint inhibitors. Scand J Gastroenterol. 2019 May;54(5):538-45.
4 National Cancer Institute: Common Terminology Criteria for Adverse Events (CTCAE) 5.0. Bethesda: NCI; 2017.

5 Brahmer JR, Lacchetti C, Schneider BJ, Atkins MB, Brassil KJ, Caterino JM, et al.; National Comprehensive Cancer Network. Management of Immune-Related Adverse Events in Patients Treated with Immune Checkpoint Inhibitor Therapy: American Society of Clinical Oncology Clinical Practice Guideline. J Clin Oncol. 2018 Jun;36(17):1714-68.

6 Haanen JB, Carbonnel F, Robert C, Kerr KM, Peters S, Larkin J, et al.; ESMO Guidelines Committee. Management of toxicities from immunotherapy: ESMO Clinical Practice Guidelines for diagnosis, treatment and follow-up. Ann Oncol. 2017 Jul;28(4 suppl_4):iv119-42.
7 Dolladille C, Ederhy S, Sassier M, Cautela J, Thuny F, Cohen AA, et al. Immune Checkpoint Inhibitor Rechallenge After ImmuneRelated Adverse Events in Patients With Cancer. JAMA Oncol. 2020 Jun;6(6):865-71.

8 de Malet A, Antoni G, Collins M, Soularue E, Marthey L, Vaysse T, et al. Evolution and recurrence of gastrointestinal immune-related adverse events induced by immune checkpoint inhibitors. Eur J Cancer. 2019 Jan;106: 106-14. 